\title{
Diflufenican Dissolved in Different Aqueous Co-solvency Mixtures: Equilibrium Solubility Measurment and Thermodynamic Modeling
}

\author{
Renjie Xu*, Chunjuan Huang, Haixia Zhang \\ Guangling College, Yangzhou University, Yangzhou, Jiangsu 225000, People’s Republic of China
}

Corresponding author. Phone: + 86514 87993918; Fax: + 8651487994009 .

E-mail address: xurenjie126@163.com. 


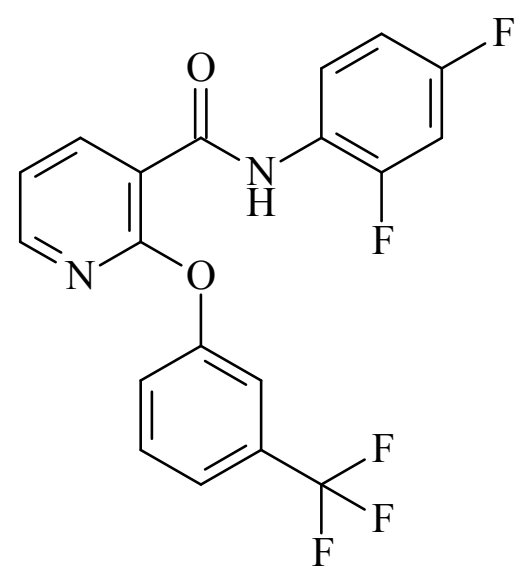

Fig. S1. Chemical structure of diflufenican. 


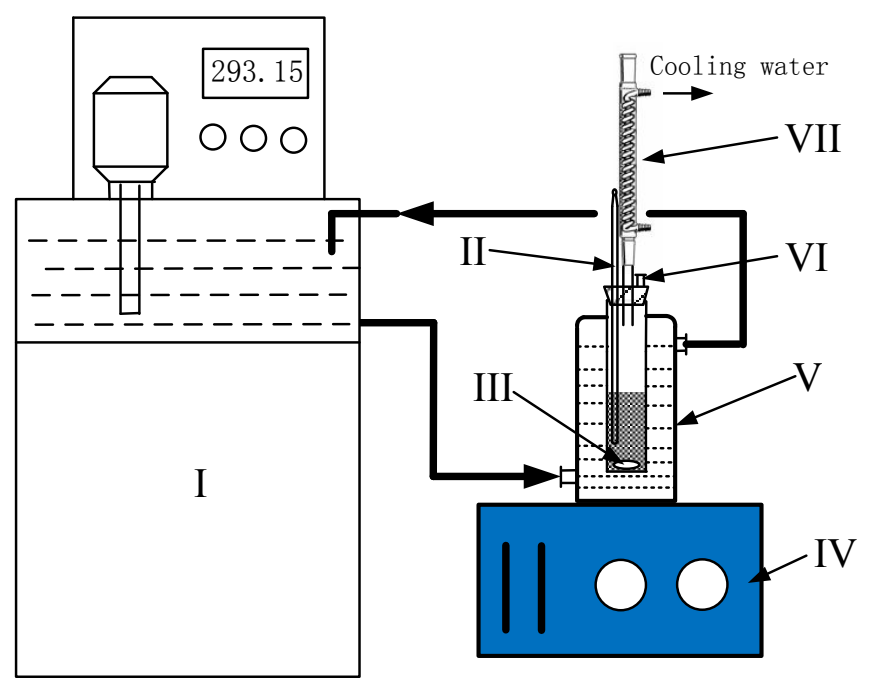

Fig. S2. Schematic diagram of experimental apparatus: I, smart thermostatic water bath; II, mercury-in-glass thermometer; III, magnetic stirrer; IV, stirrer controller; V, jacketed glass vessel; VI, sampling port; VII, condenser. 




Fig. S3. XPRD patterns of diflufenican: (a) raw material; (b) crystallized in ethanol; (c) crystallized in PG; (d) crystallized in EG; (e) crystallized in DMF; (f) crystallized in water; (g) crystallized in ethanol + water mixture; (h) crystallized in PG + water mixture; (i) crystallized in EG + water mixture; (j) crystallized in DMF + water mixture. 


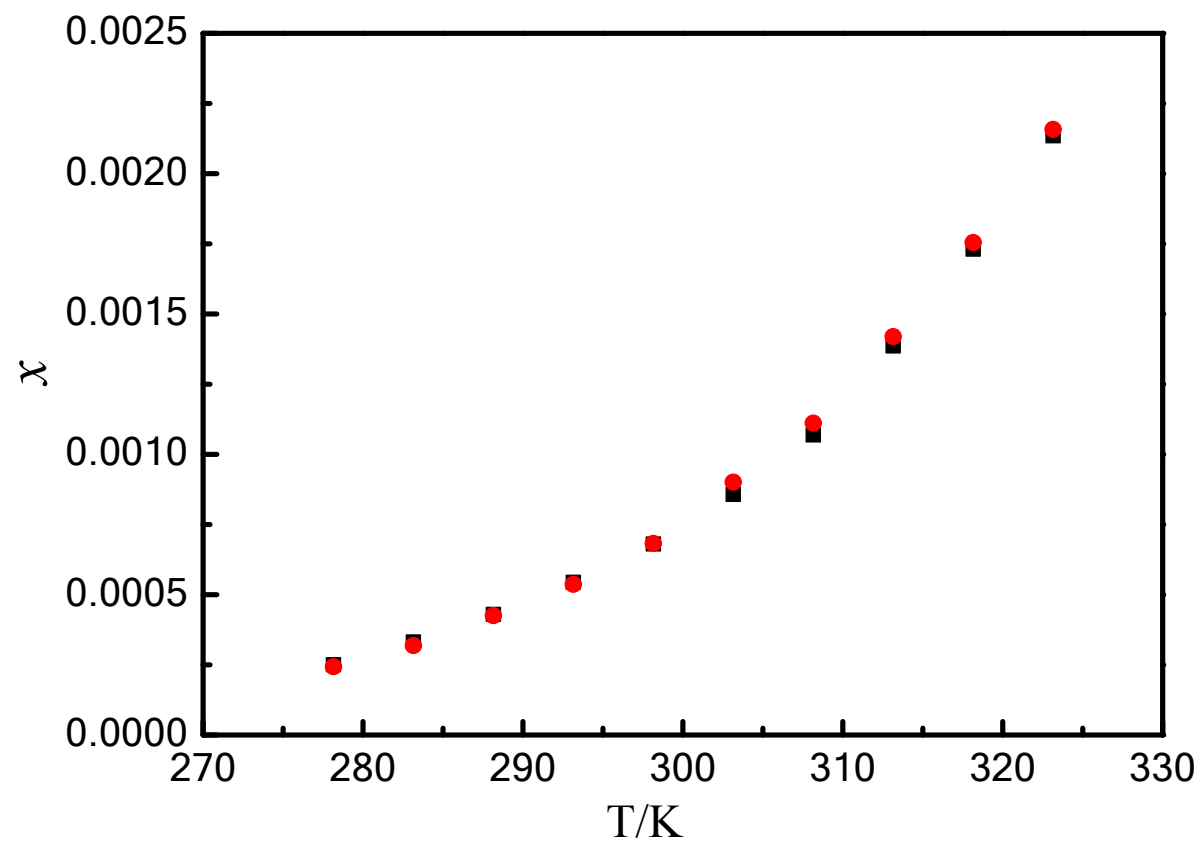

Fig. S4. Mole fraction solubility $(x)$ of diflufenican in ethanol determined in this work and reported in the previous publication: $\boldsymbol{\bullet}$, this work; $\mathbf{\square}$, taken from Ref. [1]. 


\section{REFERENCES}

(1) Song, L. C.; Zhao, D. Y.; Zhang, S. G.; Zhang, X.; Wang, G.; Zhu, C. Q.; Tian, Y.; Yang, C. H. Solubility of Diflufenican in Pure and Binary Solvent Systems. J. Chem. Eng. Data. 2018, 63, 4176-4184. 